\title{
Vascular Breast Neoplasm
}

National Cancer Institute

\section{Source}

National Cancer Institute. Vascular Breast Neoplasm. NCI Thesaurus. Code C5209.

A benign or malignant vascular neoplasm that arises from the breast. 